\title{
Mother's Knowledge of Initiative Breast Feeding in Relation to Neonatal Jaundice
}

\author{
Nuhad Mohammed Al Doori' ${ }^{1}$, Wafaa Ahmed Ameen ${ }^{2}$, Mohommed Talib ${ }^{3}$ \\ ${ }^{1}$ Assist. Prof. Dr. College of Nursing, University of Babylon, Iraq; ${ }^{2}$ Lecturer, Dr. College of Nursing, University of \\ Babylon, Iraq, ${ }^{3}$ Assist. Lecturer, College of Nursing, University of Babylon, Iraq
}

\begin{abstract}
Jaundice is the greatest common situation that needs medicinal care in neonates, which present as yellow coloration of the skin and sclera related to accumulation of unconjugated bilirubin which was considered a neurotoxic to cause brain death (Kernicterus). The Aim of this study to identify the effect of successful breast feeding on neonatal hyperbillirubinemia. Material \& method: Design a descriptive design was conducted through a period of study. The sample \& setting: were taken accidentally from (250) mothers who had children under one year from practicing breast feeding from Babel maternity and pediatric hospital. Data collection were collected through structured interview and application of the questionnaire with mothers regarding their early achievement of breast fed their jaundiced .Self-administered instrument which takes about 30 minutes. Data analysis: data analyzed the equal number of mother's age were $(43.2 \%)$ who were aged $(26-31)$, with majority $(47.2 \%)$ of the sample were not educated, therefore that $(92.0 \%)$ were not working. The researchers recommend educational booklets construction concerning the ten steps of successful breast feeding.
\end{abstract}

Keyword: Neonatal Jaundice, Initiative Early Breast Feeding

\section{Introduction}

Newborn jaundice is the most widespread situation affecting neonatal babies particularly throughout the first week of life. Approximately fifty percent to sixty percent of the neonatal babies become affected with jaundice in the first week of life besides, global, around 14.1 million neonatal babies requirement phototherapy to treat jaundice ${ }^{(1)}$.Moreover, ${ }^{(2)}$ mentioned that global, there are approximately 0.5 to 4 percent of term, early term and late preterm children from 135 million yearly live births, before discharge from the nursery obtain phototherapy. Jaundice, a common situation in neonates, refers to the whites of the eyes, and yellow color of the skin that occurs when there is excessively bilirubin in the blood. Bilirubin (bill-uh-ROO-bin) is made by the normal breakdown of red blood cells(RBCs). Normally, it passes through the liver, which releases it into the intestines as bile (a liquid that helps with digestion). ${ }^{(3)}$

Newborn jaundice is the most common problem in full-term babies throughout the immediate post-natal period . Nurses' breastfeeding beliefs, knowledge, and behaviors can significantly affect mothers' breastfeeding success. However, mothers of infants admitted to hospital with jaundice experience feelings of failure, guilt and inadequacy. Maternal confidence is known to be a strong predictor of breastfeeding duration, with absence of confidence in breastfeeding skills leading to a higher likelihood of weaning in the first 6 weeks post-partum (4). The affiliation concerning newborn jaundice and initial breast feeding initiation has acknowledged much consideration, as long as, it is a result of numerous factors which may be maternal or fetal related. Jaundice can be either maternal or fetal related, in most cases treatment is not essential just as continuity on breast feeding. (1) .To improve the growth, overall health of children, and nutritional status, the World Health Organization and the United Nations Kids' Fund stimulate a worldwide strategy for baby and young kid feeding, which involve the Baby- Friendly Hospital Initiative and ten steps for successful breast-feeding, which has a important effect on the grade of jaundice, ${ }^{(4)}$. 
Breastfeeding confers many advantages to infants, mothers, families, and society and is the normal nutrition for the newborn infant. Human milk infant feeding decreases the incidence of infectious diseases and enhances the immunologic status of the newborn , exclusive breastfeeding is therefore recommended for the first six months of life ${ }^{(4)}$.

Notwithstanding of "many advantages of breast-feeding, previous medical reports revealed that dehydration, poor body weight gain, and hyperbilirubinemia in breast-fed infants are more common. These problems were often preventable and generally did not result in long-term harm to the infants; however, in recent years, serious consequences, such as hypernatremic dehydration and kernicterus have been reported in exclusively breast-fed infants. The causes may be attributed to inappropriate breast-feeding and to early discharge practices". (3"which includes breastfeeding classes, 24-hour rooming-in, and exclusive breast-feeding. In Since many years ago, our hospital has been promoting the Baby- Friendly Hospital Initiative, our experience; many mothers have concerns about breast-feeding, including breast-milk insufficiency, decreased infant urination, poor body weight gain, and jaundice". (5)

Baby-Friendly practices are based on the foundation that individual attitudes toward breastfeeding are largely influenced by breastfeeding education during the early prenatal period, positive birth and initial breastfeeding experiences, and continued provider support ${ }^{(6)}$.

\section{Objectives of the Study}

The main objective of this research is listed in the following points:

1) To determine the mother's knowledge concerning initiative breast feeding .

2) To identify the relationship between initiative breast-feeding with neonatal jaundice and such demographic data.

\section{Methodology}

Design of the study: Correlation design conducted to study the association between the neonatal jaundice with initiative breast feeding through the period
Dec.2017-Feb.2018.

Sample of the study: probability (purposive sampling) was selected which consists of" (250) mothers who were admitted to pediatric words at Babylon hospital for maternal and children.

Setting of the study: the study carried out at Babylon hospital maternal and child.

The study carried out at Babel maternity and pediatric hospital

Instruments: The questionnaire was assembled for the purpose of the study. The Instruments consisted"

Part 1: Demographic Date Sheet: This part concerned with personal information include"

Part 2: items related to Mothers knowledge according to WHO instructions for Initiative Breast Feeding

Statistical Analysis: Data were analyzed using the Statistical Package for Social Sciences" (SPSS) "version 19. Through the application of descriptive statistical data analysis include" (Frequencies and Percentage).

\section{Results}

(43.2\%) of mothers age where between 26-31, concerning level of education about $(47.2 \%)$ where not educated, in regarding type of delivery (52\%) from them where normal vaginal delivery, concerning disease $82 \%$ have not any chronic disease, according to medication $85 \%$ where no, in regarding sex $58 \%$ where female, concerning gestational age $84 \%$ where less than 37 , according to Age newborn 35.2\% where between 1-5 days, concerning Weight at birth (46.8) where weight between 2600-3100 gm, in regarding Type of feeding (65.2) where breast feeding. Concerning Child order (41.2) where first child. In regarding to jaundice (76) their children with jaundice, according to Type of management (56.8) where with phototherapy. Initiative successful breast feeding ( 78) where No, according to Initial first feeding within first half an hour( 56) were No. concerning Lactate my baby on demands (63.2) where No, in regarding to Lactate my baby on schedule(63.2) where No. according to Exclusive breastfeeding under 6 month (62.4) where No, concerning Take lessons about importance of breast feeding through pregnancy (63.2) 
where No. in regarding to Begin with sugar \& water support breast feeding (63.2) where No. concerning Evacuate one side on each time of feeding (66.4) where No. according to Lactate baby from both sides equal time (60.8). concerning Using my nipple areola on sucking (64) where No. in regarding I used to keep may baby on pacifier between breast feeding (55.2) where No, according to -I gave my baby such remedies between Br. Milk (63.2) where No, concerning Remedies used once a day in addition to breast milk (64) where No and in regarding Continue on breast feeding with elevation of bilirubin(62.4) where No.

Table (1): Association between mothers characteristics as age with Jaundice ( $N=250)$

\begin{tabular}{|c|c|c|c|c|c|c|}
\hline $\begin{array}{l}\text { jaundice } \\
\text { Age }\end{array}$ & Yes & No & Total & $\chi_{\text {obs. }}^{2}$ & Df & $\chi_{\text {crit }}^{2} \chi_{\text {crit }}^{2}$ \\
\hline $20-25$ & 30 & 5 & 35 & \multirow{4}{*}{2.679} & \multirow{4}{*}{2} & \multirow{4}{*}{5.991} \\
\hline $26-31$ & 78 & 30 & 108 & & & \\
\hline 32 and more & 82 & 25 & 107 & & & \\
\hline Total & 190 & 60 & 250 & & & \\
\hline
\end{tabular}

p-value $=061$

This table reveal that no relationship between mothers age and jaundice at p-value $(0.61)$

Table (2): Association between mothers characteristics as level of Education with Jaundice ( $N=250)$

\begin{tabular}{|l|l|l|l|l|l|l|}
\hline $\begin{array}{l}\text { jaundice } \\
\text { Education }\end{array}$ & Yes & No & Total & $\chi_{\text {obs. }}^{2}$ & Df & $\chi_{\text {crit }}^{2} \chi_{\text {crit. }}^{2}$ \\
\cline { 1 - 5 } Not educated & 82 & 36 & 118 & & & \\
\cline { 1 - 4 } & 78 & 19 & 97 & \multirow{2}{*}{5.587} & 2 & \multirow{2}{*}{5.991} \\
\cline { 1 - 5 } Well Educated & 30 & 5 & 35 & & \\
\hline Total & 190 & 60 & 250 & & \\
\hline
\end{tabular}

$\mathrm{p}$-value $=0.61$

"This table reveal that no statistical significant relationship between mother's level of education and jaundice at p-value" $(0.61)$

Table (3): Association between mothers characteristics as Occupation with Jaundice ( $\mathrm{N}=\mathbf{2 5 0})$

\begin{tabular}{|l|l|l|l|l|l|l|}
\hline $\begin{array}{l}\text { jaundice } \\
\text { Occupation }\end{array}$ & Yes & No & Total & $\chi_{\text {obs. }}^{2}$ & Df & $\chi_{\text {crit }}^{2} \chi_{\text {crit. }}^{2}$ \\
\hline Not Working & 175 & 55 & 230 & \multirow{2}{*}{0.012} & 1 & \multirow{2}{*}{3.841} \\
\hline Working & 15 & 5 & 20 & & & \\
\hline Total & 190 & 60 & 250 & & \\
\hline
\end{tabular}

p-value $=0.913$ 
This table reveal that no statistical significant relationship between mother's occupation and jaundice at p-value $(0.91)$

Table (4): Association between mothers characteristics as type of delivery with Jaundice $(\mathrm{N}=\mathbf{2 5 0})$

\begin{tabular}{|c|c|c|c|c|c|c|}
\hline $\begin{array}{l}\text { jaundice } \\
\text { Type of } \\
\text { Delivery }\end{array}$ & Yes & No & Total & $\chi_{\text {obs. }}^{2}$ & Df & $\chi_{\text {crit }}^{2} \chi_{\text {crit }}^{2}$ \\
\hline Normal delivery & 95 & 35 & 130 & \multirow{3}{*}{012} & \multirow{3}{*}{1} & \multirow{3}{*}{3.841} \\
\hline CS & 95 & 25 & 120 & & & \\
\hline Total & 190 & 60 & 250 & & & \\
\hline
\end{tabular}

p-value $=0.260$

This table reveal that no statistical significant relationship between mother's type of delivery and jaundice at p-value (0.26)

Table (5): Association between mothers characteristics as chronic disease with Jaundice $(\mathrm{N}=\mathbf{2 5 0})$

\begin{tabular}{|l|l|l|l|l|l|l|}
\hline $\begin{array}{l}\text { jaundice } \\
\text { Chronic } \\
\text { Disease }\end{array}$ & Yes & No & Total & $\chi_{\text {obs. }}^{2}$ & df & $\chi_{\text {crit }}^{2} \chi_{\text {crit. }}^{2}$ \\
\cline { 1 - 5 } Yes & 35 & 10 & 45 & 095 & 1 & \multirow{2}{*}{3.841} \\
\hline No & 155 & 50 & 205 & & \\
\hline Total & 190 & 60 & 250 & \\
\hline
\end{tabular}

p-value $=0.758$

This table reveal that no statistical significant relationship between mother's chronic disease and jaundice at p-value (0.75)

\section{Discussion}

The present study has reported that the highest percentage $(43.2 \%)$ of the study sample is at age group ranged" (26 - 31) "years old. This study is disagrees with (7) study that found the age range" (20-30)years. "On other side, it agree with ${ }^{(6)}$ study which done in Nigeria when reported that the highest percent" (58.5\%) of the study sample is at age group ranged $(\leq 30)$ years old. ${ }^{(4)(3)}$ Concerning level of education (47.2\%) of the sample were not educated Which likely to be inconsistent with (Pound,2015) study that who revealed that (57.1) $\&$ (56.0) of mothers were Completed university. The highest percent of the respondents $(92.0 \%)$ were not working, which disagree with ${ }^{(7)}$ study done in Nigeria that showed high rates of awareness of EBF among working class mothers. In regarding type of delivery $(52 \%)$ from them where normal vaginal delivery ,study ${ }^{(9)}$ present that $(62.5 \%)$ of neonates with normal vaginal delivery Concerning disease $(82 \%)$ of sample were not have any chronic disease. ${ }^{(8)}$ and ${ }^{(11)}$ present their sample with no disease through gestation, which reliable with the present study outcome when the respondents have no disease as antenatal. The present study shows that $85 \%$ where not taking medication, while in a study of ${ }^{(8)}$ who found that the highest percentage $(89.0 \%)$ of mothers were oxytocin infusion during labor which may be related to absence of chronic disease .The gender of neonate $(58 \%)$ where female. as the same output of (11) who found that the highest percentage (48.3) of neonate were 
female . Majority of the babies included were (84.0\%) were gestational age less than 37 weeks, with $(35.2 \%$ ) where between 1-5 days age begin to complain from yellowish discoloration. it looks like not the same result of ${ }^{(9)}$ study who present his sample as (78.0) of full term were gestational age. Type of feeding among the babies of the mothers included were the highest percentage (65.2) with breast feeding, which dis agreement with ${ }^{(10)}$ found that increase infant enteral intake There is a positive association between number of breastfeeds a day and lower TSB. According to type of management (56.8) where management with phototherapy, as well as (11)found that $(82.9 \%)$ received phototherapy . Also in agreement with ${ }^{(12)}$ found that when TSB levels rise above the thresholds stated in guidelines, despite adequate lactation support, phototherapy is recommended as the most effective treatment. Concerning weight at birth (46.8) where weight between 2600-3100 gm., which is alike of ${ }^{(10)}$ study who found that the highest percentage (71.3)of neonate were normal weight. The present study found the child order were the first, which in agreement with (15) "who found that The primi para mother is the one of the risk factor of neonatal jaundice. The primi para mother have totaly 23 present the total case. that is the $30 \%$ neonatal jaundice effected in the case of primi para mother". ${ }^{(15)}$ stated that some herbal remedies taken by the lactating mother may apparently exacerbate jaundice in the infant.

\section{Association}

This study reveal that no relationship between mothers age and jaundice at p-value (0.61)., which incongruent with (Tavakolizadeh,2018) who found that the maternal age was significantly associated with different levels of bilirubin $(p=0.02)$, indicating a significant correlation of maternal age with incidence of jaundice.

"Moreover, there is no statistical significant relationship between mother's level of education and jaundice at p-value" $(0.61)$ "This result is in agreed with (10) who found that the level of education was found that not significant relationship with Jaundice p-value"( 0.176).

Scientifically and logically which based on literatures, highly significant relation should be between mother's occupation, type of delivery and jaundice, as mentioned by ${ }^{(10)}$, even though the present results was no statistical significant relationship.

This present study result reveal that no statistical significant relationship between mother's chronic disease and jaundice at $p$-value $(0.75)$, which congruent with ${ }^{(14)}$ who found that found that there is no significant relationship found in the familiar history of diabetes, anemia ,thalassemia) among neonates with different levels of bilirubin $(P=0.2,0.3, P=0.06)$

Financial Disclosure: There is no financial disclosure.

Conflict of Interest: None to declare.

Ethical Clearance: All experimental protocols were approved and all experiments were carried out in accordance with approved guidelines.

\section{References}

1. Mugadza G, Zvinavashe M, Gumbo Z, StrayPedersen B. Early breastfeeding initiation and incidence of severe neonatal jaundice in Chipinge district Zimbabwe. International Journal of Contemporary Pediatrics, 2017; 4(6): 1922.

2. Pound CM, Moreau K, Rohde K, Barrowman N, Aglipay M. Lactation support and breastfeeding duration in jaundiced infants: a randomized controlled trial. PloS one. 2015; 10(3): e0119624.

3. Olusanya B, Osibanjo F. The burden and management of neonatal jaundice in Nigeria: A scoping review of the literature. Nigerian journal of clinical practice. 2016; 19(1): 1-17.

4. Merten S, Dratva J, Ackermann-Liebrich U. Do baby-friendly hospitals influence breastfeeding duration on a national level?. Pediatrics. 2005; 116(5): e702-e708.

5. Lin Y, Tsao P, Hsieh W. The impact of breastfeeding on early neonatal jaundice. Clin Neonatol. 2008; 15(1): 31-35.

6. Mbada C, Olowookere A. Knowledge, attitude and techniques of breastfeeding among Nigerian mothers from a semi-urban community, BMC Research Notes. 2013; 6: 552.

7. Chen C, Hsu M, Shen C. Influence of breast-feeding on weight loss, jaundice, and waste elimination in neonates. Pediatrics \& Neonatology. 2011; 52(2): 85-92 
8. Mojtahedi S, Izadi A. Risk Factors Associated with Neonatal Jaundice: A Cross-Sectional Study from Iran. Open access Macedonian journal of medical sciences. 2018; 6(8): 1387.

9. Xavier R, Manoj C, Cherian V. Breastfeeding jaundice: how big is the problem? International Journal of Contemporary Pediatrics 2016; 3: 498503.

10. Adoba P, Ephraim R, Kontor K. Knowledge Level and Determinants of Neonatal Jaundice: A Cross-Sectional Study in the Effutu Municipality of Ghana. March 2018International Journal of Pediatrics 2018; (2):1-9

11. Kale A, Sharma P, Jain A, Gajare B. Factors identifying babies at risk for significant hyperbilirubinemia: a prospective study conducted at a tertiary care center. International Journal of Contemporary Pediatrics .2016;3(4): 1262-1266
12. Burke BL, Robbins JM, Bird TM, Hobbs CA, Nesmith C, Tilford JM. Trends in hospitalizations for neonatal jaundice and kernicterus in the United States, 1988-2005. Pediatrics.2009. 123: 524-32.

13. Olusanya B, Akande A, Emokpae A. Infants with severe neonatal jaundice in Lagos, Nigeria :incidence, correlates and hearing screening outcomes.Tropical Medicine and International Health. 2009; 14 ( 3) :301-310

14. Valerie R, Flaherman M. Guidelines for Management of Jaundice in the Breastfeeding Infant 35 Weeks or More of Gestation-Revised 2017, BREASTFEEDING MEDICINE. 2017; 12,( 5)

15. ANEES T. RETROSPECTIVE ASSESSMENT AND MANAGEMENT OF NEONETAL JAUNDICE CASES IN GOVERNMENT HOSPITAL TIRUPUR .2018 